\title{
The Atypical Spitz Tumor of Uncertain Biologic Potential
}

\section{A Series of 67 Patients From a Single Institution}

I read with interest the recent article by Ludgate et al, ${ }^{1}$ who reported on a large series of atypical Spitz tumors (ASTs), a subgroup of ambiguous tumors that have histologic features of Spitz nevi mixed with features of melanoma and, thus, are difficult to diagnose. In such patients, sentinel node biopsy has been proposed with the hypothesis that, if any metastasis is detected, then it represents proof that the lesion was malignant. To date, 117 patients with ASTs who underwent sentinel node biopsy have been reported, and 50 of those patients had lymph node lesions. ${ }^{1}$ Such melanocytic deposits have been interpreted mostly as micrometastases; however, because the possibility that they represent only benign nevi also was considered, the consequent discussion developed by the authors on this topic risks diminishing the possible diagnostic value of sentinel node biopsy in patients with these tumors.

Undoubtedly, the incidence of melanocytic deposits in sentinel lymph nodes from patients with ASTs (42.7\%) differs dramatically from that of lymph node nevi in sentinel lymph nodes from patients with melanoma (3.9\%). ${ }^{2}$ However, because diagnostic criteria with which to differentiate lymph node micrometastases from lymph node nevi exist and seem to work, ${ }^{2}$ all lymph node lesions should be diagnosed using the same histologic criteria, irrespective of the diagnoses made on synchronous cutaneous tumors. In fact, it does not seem reasonable to diagnose a lymph node lesion as metastasis if the cutaneous lesion was labeled as melanoma and to diagnose a lymph node lesion that has the same characteristics differently if the cutaneous tumor was classified otherwise. If to diagnose a cutaneous tumor using data derived from a lymph node is illogical, ${ }^{3}$ then, in the same way, it must be illogical to use data derived from a cutaneous tumor to diagnose a lymph node lesion.

\section{REFERENCES}

1. Ludgate MW, Fullgen DR, Lee J, et al. The atypical Spitz tumor of uncertain biologic potential: a series of 67 patients from a single institution. Cancer. 2009;115:631-641.

2. Holt JB, Sangueza OP, Levine EA, et al. Nodal melanocytic nevi in sentinel lymph nodes. Correlation with melanoma-associated cutaneous nevi. Am J Clin Pathol. 2004;121:58-63.
3. Medalie N, Ackerman AB. Sentinel node biopsy has no benefit for patients whose primary cutaneous melanoma has metastasized to a lymph node and therefore should be abandoned now. Br J Dermatol. 2004;151:298-307.

Carmelo Urso, MD
Dermatopathology Section
Department of Anatomic Pathology and Laboratory Medicine
S. M. Annunziata Hospital
Florence, Italy

DOI: 10.1002/cncr.24692, Published online: October 27, 2009 in Wiley InterScience (www.interscience.wiley.com)

\section{Reply to The Atypical Spitz Tumor of Uncertain Biologic Potential}

\section{A Series of 67 Patients From a Single Institution}

We thank Dr. Urso for his comments on a difficult topic. ${ }^{1}$ In conventional melanoma, distinguishing between melanoma micrometastases and benign lymph node nevi usually is possible based on established criteria. However, this distinction can be less clear with many rarer melanocytic lesions, including atypical Spitz tumors (ASTs). For example, cellular blue nevi may have melanocytic deposits within the parenchyma and subcapsular sinus of lymph nodes, a location typically associated with conventional metastases. ${ }^{2}$ Conversely, benign intraparenchymal lymph node nevi have been reported in other benign melanocytic lesions. ${ }^{3}$ In these patients, the classification and features of the primary cutaneous lesion is vital in determining the nature of the lymph node deposit. If the lymph node deposits are viewed in isolation, then they could be interpreted erroneously as malignant metastasis. We do not know whether conventional Spitz nevi (agreed on by a consensus of experts as lacking sufficient criteria for spitzoid melanoma or AST) are capable of a similar phenomenon of having benign parenchymal or subcapsular sinus lymph node deposits that mimic malignant micrometastases, as suggested by LeBoit. ${ }^{4}$ If this phenomenon does occur in conventional Spitz nevi, then the cytologic features of the primary cutaneous lesion become even more relevant, and it is paramount to evaluate the cytologic features of the lymph node deposits in the context of the primary lesion. Therefore, although it is 
possible that many of the lymph node deposits we observed in ASTs were malignant micrometastases, we believe that the possibility of a benign process cannot be entirely excluded. We agree that the incidence of lymph node positivity in our series of AST is high (47\%) compared with the incidence of lymph node nevi (range, $1 \%-22 \%)$ reported in series of conventional melanoma. ${ }^{5,6}$ However, because the incidence of benign lymph node deposits in conventional Spitz nevi is unknown (and likely will never be known), the reason for and significance of this discrepancy is unclear. Hopefully, future molecular insights in ASTs and their sentinel lymph node deposits may be able to shed some light onto their true nature.

\section{REFERENCES}

1. Ludgate MW, Fullen DR, Lee J, et al. The atypical Spitz tumor of uncertain biologic potential: a series of 67 patients from a single institution. Cancer. 2009;115:631-641.

2. Azzopardi JG, Ross CM, Frizzera G. Blue naevi of lymph node capsule. Histopathology. 1977;1:451-461.

3. Biddle DA, Evans HL, Kemp BL, et al. Intraparenchymal nevus cell aggregates in lymph nodes: a possible diagnostic pitfall with malignant melanoma and carcinoma. Am J Surg Pathol. 2003;27:673-681.
4. LeBoit PE. What do these cells prove? Am J Dermatopathol. 2003;25:355-356.

5. Carson KF, Wen DR, Li PX, et al. Nodal nevi and cutaneous melanomas. Am J Surg Pathol. 1996;20:834-840.

6. Holt JB, Sangueza OP, Levine EA, et al. Nodal melanocytic nevi in sentinel lymph nodes. Correlation with melanomaassociated cutaneous nevi. Am J Clin Pathol. 2004;121:58-63.

$$
\begin{array}{r}
\text { Mathew W. Ludgate, MBChB } \\
\text { Department of Dermatology } \\
\text { Aniversity of Michigan Medical School and Comprehensive Cancer Center } \\
\text { Ann Arbor, Michigan } \\
\text { Douglas R. Fullen, MD } \\
\text { Department of Dermatology; Department of Pathology } \\
\text { Aniversity of Michigan Medical School and Comprehensive Cancer Center } \\
\text { Ann Arbor, Michigan } \\
\text { Lori Lowe, MD } \\
\text { University of Michigan Medical School and Comprehensive Cancer Center } \\
\text { Ann Arbor, Michigan } \\
\text { Timothy M. Johnson, MD } \\
\text { University of Michigan Medical School and Comprehensive Cancer Center } \\
\text { Ann Arbor, Michigan }
\end{array}
$$

DOI: 10.1002/cncr.24694, Published online: November 6, 2009 in Wiley InterScience (www.interscience.wiley.com) 